\title{
THE DIFFERENCES OF CORRELATIONOF THE TIMI, GRACE, AND KILLIP RISK SCORES AS PREDICTOR PROGNOSIS PATIENTS WITH NON ST-ELEVATION MYOCARD INFARCTION ACUTE CORONARY SYNDROME IN ICCU RSUD DR. ISKAK TULUNGAGUNG
}

\author{
Rina Anggraini I.S', Titin Andri Wihastuti', Dewi Kartikawati Ningsih ${ }^{2}$ \\ ${ }^{1}$ Ulin General Hospital Banjarmasin Indonesia \\ ${ }^{2}$ Master of Nursing Program, Faculty of Medicine, Universitas Brawijaya Malang Indonesia
}

\begin{abstract}
Acute Coronary Syndromes is the leading cause of short-term and long -term mortality.An aggressive treatment approach has the potential to change the prognosis of patients with ACS, although its depends on risk factors. There are several risk scores such as Thrombholysis in Myocardial Infarction (TIMI), Global Registry of Acute Coronary Events (GRACE), and Killip. The aim of this study is to analyse the differences of correlation of TIMI, GRACE, and Killip risk scoresas predictor Length Of Stay patientswith Non St-Elevation Myocard Infarction ACS.The method of this study utilized an analytic observational design with the cohort retrospective. The research was conducted at RSUD Dr.lskak Tulungagung used 98 samples of medical records patient with NSTEMI ACS in the past 8 months (January-August 2017). The data collection techniques was completing risk score of TIMI, GRACE, and Killip and Length of Staypatient in ICCU ward. The results and analyse of Spearman Rank showed that TIMI has $p=0,000 r=0.466$, GRACE $p=0,000 r=0.598$, and Killip $p=0,000 r=0.441(p<0,05)$, so that it can be said that there was significant differences between the risk score of TIMI, GRACE and Killip as predictor prognosis patient with NSTEMI ACS. It can be concluded that the TIMI, GRACE and Killip risk scores have correlationas predictor prognosis patient with NSTEMI ACS, which is GRACE risk score has superior to TIMI and Killip.
\end{abstract}

Keywords : NSTEMI ACS, Risk Scores (TIMI, GRACE, Killip), Length of Stay (LOS)

\begin{abstract}
ABSTRAK
Penyakit Sindrom Koroner Akut (SKA) masih menjadi penyebab kematian tertinggi dalam jangka panjang maupun jangka pendek. Pengobatan secara agresif memiliki potensi lebih baik dalam mengubah prognosis pasien dengan SKA, meskipun seringkali bergantung pada faktor risiko, sehingga diperlukan pengkajian pasien. Terdapat beberapa skor risiko yang digunakan antara lain: Thrombholysis in Myocardial Infarction (TIMI), Global Registry of Acute Coronary Events (GRACE), dan Killip. Tujuan dari penelitianadalah untuk menganalisis perbedaan korelasi skor TIMI, GRACE, dan Killip sebagai prediktor Length of Stay (LOS) pada pasien SKA Non ST Elevation Myocard Infarction (NSTEMI). Penelitian ini menggunakan desain analitik observational, metodepengambilan data secara cohort retrospective. Pelaksanaan penelitian di RSUD Dr.lskak Tulungagung dengan sampel 98 data rekam medik mulai Januari sampai Agustus 2017. Pengumpulan data dengan mengukur skor TIMI, GRACE, dan Killip pada pasien SKA NSTEMI dan dihitung lama rawat mulai masuk sampai keluar ruang ICCU, data dianalisa dengan uji korelasi Spearman Rank. Hasil analisis data menunjukkan skor TIMI $p=0.000$ dan $r=0.466$, skor GRACE $p=0.000 r=0.598$, dan skor Killip $p=0.000 r=0.441$ pada rentang $\mathrm{p}<0,05$, sehinggaterdapat perbedaan korelasi secara signifikan antara skor TIMI, GRACE, dan Killip dengan Length of Stay (LOS) pada pasien SKANSTEMI yang dirawat inap di ICCU Dr.Iskak Tulungagung. Peneliti menyimpulkan bahwa terdapat perbedaan korelasi antara skor TIMI, GRACE, dan Killip sebagai prediktor prognosis pada pasien SKA NSTEMI. Skor GRACE memiliki korelasi paling kuat sebagai prediktor prognosis dibandingkan skor TIMI dan Killip, untuk digunakan dalam pengkajian pasien.
\end{abstract}

Kata kunci: SKA NSTEMI, Skor Risiko (TIMI, GRACE, Killip), Length of Stay (LOS)

Jurnal Ilmu Keperawatan Vol. 6, No. 1 Mei 2018. Korespondensi : Rina Anggraini. Rumah Sakit Umum Daerah Ulin Banjarmasin. Email: indah_unlam@yahoo.co.id

www.jik.ub.ac.id 


\section{PENDAHULUAN}

Penyakit kardiovaskular merupakan kelompok penyakit yang terletak di jantung dan pembuluh darah termasuk didalamnya antara lain penyakit pada bagian jantung koroner (PJK), arterial jantung, dan pasien dengan Sindrom Koroner Akut (SKA). Penyakit SKA dikarakteristikan dengan arteri yang mengalami aterosklerosis dan bisa bersifat asimptomatik. Selain itu, gejala yang timbul dapat berupa nyeri seperti pada kondisi angina tidak stabil, infark miokard dengan elektrokardiogram menunjukkan segmen STdepresi (NSTEMI) dan infark miokard dengan elektrokardiogram menunjukkan segmen ST elevasi (STEMI) (World Health Organization, 2011; Lippi, et al., 2016).

Penelitian menunjukkan pengobatan secara agresif seperti Percutaneus Coronary Intervention $(\mathrm{PCl})$ memiliki potensi lebih baik dalam mengubah prognosis pasien SKA, meskipun seringkali bergantung pada faktor risiko yang dimiliki pasien. Oleh karena itu diperlukan pengkajian faktor risiko pada pasien secara lengkap sehingga dapat digunakan sebagai pedoman strategi pengobatan dan perawatan pasien dengan tepat (Bueno \& Aviles, 2012).

Terdapat beberapa skor risiko yang paling sering digunakan di Indonesia dalam praktek klinis yaitu TIMI, GRACE dan Killip. Skor risiko sebagai alat bantu pada pasien SKA, dapat digunakan untuk mendukung optimalisasi terapi, menurunkan biaya kesehatan, dan memperbaiki outcome klinis pasien (Backus et al, 2011). Penelitian yang dilakukan pada 901 pasien di Iran, menunjukkan bahwa skor risiko Thrombolysis in Myocardial Infarction (TIMI) memiliki spesifisitas yang tinggi dalam memprediksi outcome klinis mortalitas dalam 30 hari, miokard infark dan perlunya revaskularisasi pada pasien SKA (Mogghadam, et al., 2016). Pada penelitian pasien NSTEMI berjumlah 21.688 skor risiko Global Registry of Acute Coronary Events (GRACE) dapat memprediksi mortalitas di rumah sakit, mortalitas 6 bulan selanjutnya dan menyediakan prediksi kuantitatif dengan rumus yang komplek (Bueno \& Avilles, 2012). Penelitian yang dilakukan pada pasien SKA sebanyak 6704 pasien menunjukkan bahwa pasien SKA dengan kelas Killip lebih tinggi memiliki profil klinis yang buruk dan secara independen dapat digunakan sebagai prediktor mortalitas pada pasien STEMI dan NSTEMI. Adapun skor risiko Killip terdiri dari 4 bagian yaitu kelas 1 pasien tanpa ada kondisi gagal jantung, sedangkan kelas Killip 2, 3, dan 4 termasuk ke dalam kondisi komplikasi dengan gagal jantung (El-Menyar et al, 2012; PERKI, 2015).

Penelitian skor risiko TIMI, GRACE dan Killip sebagai prediktor mortalitas NSTEMI dengan metode kohort prospektif belum banyak dilakukan karena memerlukan waktu yang lama dan berisiko terjadinya bias ketika tidak dapat diikuti dengan baik (LaMorte, 2016). Untuk mengantisipasi hal tersebut, penelitian skor risiko TIMI, GRACE, dan Killip sebaiknya tidak hanya melihat prognosis pasien dengan menggunakan parameter mortalitas saja, akan tetapi juga Length of Stay (LOS) agar lebih mudah melihat perkembangan pasien, sehingga akurasi dapat tercapai.

Secara etik penelitian ini kurang aplikatif jika dilaksanakan dengan rancangan kohort prospektif, selain membutuhkan waktu yang 
lama juga memiliki risiko terjadinya pelanggaran etik dalam prinsip bebas dari eksploitasi. Hal tersebut bisa terjadi karena ketika pasien telah keluar dari rumah sakit, sementara penelitian terus berjalan, maka berisiko terhadap pelanggaran prinsipprinsip etik seperti menghargai hak asasi manusia, kemanfaatan bagi pasien dan keadilan, (Nursalam, 2013). Oleh karena itu, peneliti akan menggunakan metode kohort retrospektif dalam menggali data skor risiko pada pasien NSTEMI.

Berdasarkan fenomena di atas peneliti tertarik ingin meneliti apakah terdapat perbedaan korelasi skor risiko TIMI, GRACE dan Killip sebagai prediktor prognosis pada pasien SKA NSTEMIdi ICCU Rumah Sakit Dr. Iskak Tulungagung.

\section{METODE}

Penelitian ini menggunakan desain analitik observational, metodepengambilan data secara cohort retrospective. Pelaksanaan penelitian di RSUD Dr. Iskak Tulungagung dengan sampel 98 data rekam medis pasien yang dirawat inap mulai Januari sampai Agustus 2017. Pengumpulan data dengan mengukur skor TIMI, GRACE, dan Killip pada pasien SKA NSTEMI dan dihitung lama rawat inap mulai masuk sampai pasien keluar ruang ICCU, data diolah dengan uji korelasi Spearman Rank.

\section{HASIL PENELITIAN}

\section{Analisa Univariat}

\section{Karakteristik Responden}

Tabel 1 menunjukkan bahwa responden memiliki umur dengan mean 63.8 dengan standar deviasi 10.735. Tekanan darah sistolik responden memiliki mean 128.47 dengan standar deviasi 25.712. Frekuensi denyut jantung responden memiliki median 82 dengan nilai minimum 44 dan maksimum 145. Hasil pemeriksaan laboratorium troponin responden menunjukkan nilai median 0,36 ug/L dengan nilai minimum 0.0 dan maksimum 32 .

Tabel 1. Karakteristik Subjek Berdasarkan Usia, Tekanan Darah Sistolik, Frekuensi Denyut Jantung, Kreatinin, Troponin, LOS, Skor GRACE dan Skor TIMI

\begin{tabular}{lcc}
\hline Parameter & $\begin{array}{c}\text { Mean } \\
\text { (Standar } \\
\text { Deviasi) }\end{array}$ & $\begin{array}{c}\text { Median } \\
\text { (Min-Maks) }\end{array}$ \\
\hline Umur & 63.8 & \\
Responden & $(10.735)$ & - \\
(tahun) & & \\
Tekanan Darah & 128.47 & \\
Sistolik & $( \pm 25.712)$ & - \\
(mmhg) & & \\
Frekuensi & & $(42.00$ \\
Denyut & - & \\
Jantung & & \\
(x/menit) & & 0.360 \\
Troponin & & $(0.0-9.80)$ \\
(ug/L) & - & 1.155 \\
Kreatinin & & $(0.01-$ \\
(mg/dl) & - & $32.00)$ \\
& & 3.00 \\
Skor TIMI & & $(2-5)$ \\
& - & 135 \\
Skor GRACE & & $(91-264)$ \\
& & \\
Length of Stay & & \\
(LOS) (hari) & - & \\
\hline
\end{tabular}

Hasil pemeriksaan laboratorium kreatinin responden menunjukkan nilai median 1.155 dengan nilai minimum 0.01 dan maksimum 
32.00. Pada penilaian responden dengan menggunakan skor TIMI didapatkan median sebesar 3 dengan nilai minimum 2 dan maksimum 5 .

Tabel 2. Distribusi Frekuensi Responden Berdasarkan Jenis Kelamin, Kelas Killip, dan Length of Stay (LOS)

\begin{tabular}{ccc}
\hline & Parameter & $\mathrm{n}(\%)$ \\
\hline $\begin{array}{c}\text { Jenis } \\
\text { Kelamin }\end{array}$ & Perempuan & $20(20,4 \%)$ \\
Kelas & Laki-laki & $78(79,6 \%)$ \\
Killip & Killip 1 & $74(75,5 \%)$ \\
& & \\
& Killip 2 & $11(11,2 \%)$ \\
& Killip 3 & $11(11,2 \%)$ \\
Length & Killip 4 & $2(2 \%)$ \\
of Stay & Singkat & $37(37,8 \%)$ \\
& & \\
& Menengah & $43(43,9 \%)$ \\
\hline
\end{tabular}

Berdasarkan hasil analisa data univariat didapatkan hasil sebagian besar responden berjenis kelamin laki-laki dengan jumlah 78 orang $(79.6 \%)$. Pada klasifikasi kelas Killip didapatkan sebanyak 74 orang (75.5\%) responden berada pada kategori Killip 1 . Pada kategori LOS memanjang (> 4 hari) didapatkan responden sebanyak 18 orang $(18.4 \%)$, sedangkan responden yang berada pada kategori LOS menengah (3-4hari) sebanyak 43 orang (43.9\%), dan responden yang berada pada kategori LOS singkat (? 2 hari) sebanyak 37 orang (37.8\%).

\section{Analisa Bivariat}

1. Hasil Uji Korelasi Skor TIMI, GRACE, Killip dan Length of Stay (LOS)

Berdasarkan Tabel 3 menunjukkan bahwa hasil uji korelasi Spearman Rank didapatkan perbedaan korelasi yang signifikan antara skor TIMI, GRACE, Killip dengan LOS secara berurutan yaitu skor TIMI dengan nilai signifikansi $(p)=0.000$ dan besar koefisien korelasi $(r)=0.466$, skor GRACE dengan nilai $\mathrm{p}=0.000$ dan $r=0.598$, skor Killip dengan nilai $\mathrm{p}=0.000$ dan $r=0.441$.

Tabel 3. Hasil Uji Korelasi antara Skor TIMI, GRACE, Killip dengan LOS

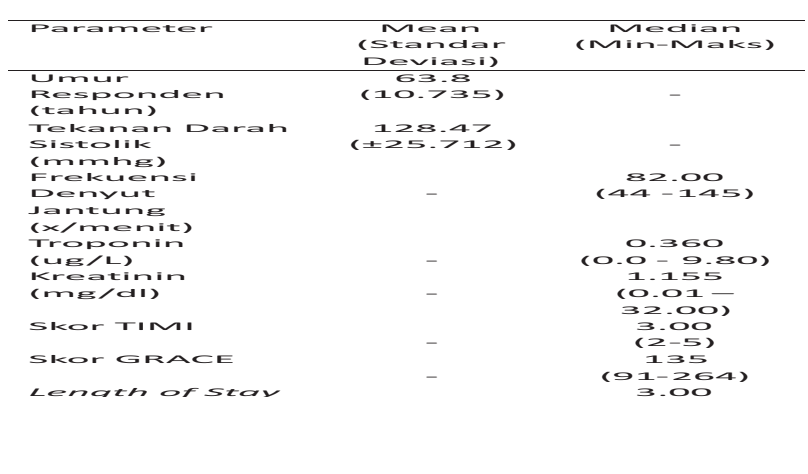

\section{PEMBAHASAN}

1. Analisis Korelasi Antara Skor Thrombholysis in Myocardial Infarction (TIMI) dan Prognosis Length of Stay (LOS) Pada Pasien Sindrom Koroner AkutNon ST Elevation Myocard Infartion (NSTEMI) di RSUD Dr. Iskak Tulungagung

Hasil analisis antara skor TIMI dan lama rawat inap pada pasien SKA NSTEMI dalam penelitian ini menunjukkan nilai signifikansi sebesar 0,000 dan koefisien korelasi sebesar 0,466 . Hal tersebut menunjukkan korelasi antar variabel skor TIMI dengan LOS memiliki kekuatan sedang, signifikan dan searah. Korelasi positif (searah) artinya jika skor TIMI tinggi maka LOS semakin memanjang (> 4 hari), sebaliknya jika skor TIMI rendah maka LOS pasien di ICCU singkat (0-2 hari).

Hal tersebut sesuai dengan hasil penelitian yang dilakukan oleh Moghaddam, et al., (2017) karakteristik dari skor TIMI 
dalam memprediksi outcome pasien selama 30 hari NSTEMI menunjukkan kekuatan dalam mendeteksi kondisi pasien dengan skor TIMI tinggi, sehingga semakin tinggi skor TIMI maka LOS pasien di rumah sakit semakin memanjang. Demikian pula pada penelitian pasien dengan skor TIMI > 4 berhubungan dengan penyakit arteri koroner dan obstruksi cabang arteri utama kiri yang dapat meningkatkan perburukan prognosis, sedangkan pada skor TIMI rendah $<4$ berhubungan dengan kondisi normal penyakit arteri ataupun tidak ada obstruksi (stenosis < 50\%), sehingga prognosis lebih baik dan LOS pasien singkat (Ben, et al., 2011; Garcia, et al., 2004, Lakhani et al., 2010).

Berdasarkan keterangan di atas dapat dikatakan skor TIMI memiliki korelasi searah, kekuatan sedang dan signifikan dengan prognosis (LOS) pada pasien SKA NSTEMI yang dirawat di ICCU.

\section{Analisis Korelasi antara Skor Global Registry of Acute Coronary Events (GRACE) dan Prognosis Length of Stay (LOS) Pada Pasien Sindrom Koroner AkutdenganNon ST Eleva- tion Myocard Infartion (NSTEMI)di RSUD dr. Iskak Tulungagung}

Hasil analisis menunjukkan korelasi antara skor GRACE dan lama rawat inap pada pasien SKA NSTEMI dengan nilai signifikansi $\mathrm{p}$ sebesar 0,000 pada rentang $95 \%(p<0,05)$ dan nilai korelasi $r$ sebesar 0.598. Hal tersebut menunjukkan korelasi antara variabel skor GRACE dengan LOS berkekuatan sedang, signifikan dan searah. Korelasi positif (searah) artinya jika semakin tinggi skor GRACE maka lama rawat inap semakin memanjang ( $>4$ hari). Hal tersebut sesuai dengan panduan dari European Society of Cardiology Clinical Practice Guidelines (2014) yang merekomendasikan skor risiko GRACE pada pasien SKA NSTEMI.

Berdasarkan tiga penelitian yang dilakukan untuk mengevaluasi hubungan laju denyut jantung dan prognosis jangka panjang, ditemukan pasien dengan laju denyut jantung meningkat (>100) memiliki prognosis buruk untuk terjadinya re-infark dan LOS yang semakin panjang (Jensen, et al., 2013; Antoni, et al., 2012; Seronde, et al., 2014). Hal tersebut didukung oleh penelitian yang menyebutkan peningkatan denyut jantung dapat meningkatkan risiko MACE (Major Adverse Cardiac Events) yaitu penurunan kondisi pada pasien kardiak, terjadinya kekambuhan miokard infark, dan stroke iskemia (Xu, et al., 2016). Hal yang sama terjadi pada penelitian ini didapatkan responden dengan skor GRACE tinggi memiliki denyut jantung meningkat $>200 \mathrm{x} / \mathrm{m}$ dan LOS yang memanjang $>4$ hari.

\section{Analisis Korelasi Antara Skor Killip dan Prognosis Length of Stay (LOS) pada pasien Sindrom Koroner Akut dengan Non ST Elevation Myocard Infarction (NSTEMI) di RSUD Dr. Iskak Tulungagung}

Pada hasil analisis penelitian ini menunjukkan korelasi antara Killip dan lama rawat inap pada pasien Sindrom Koroner Akut Non ST Elevation Myocard Infarction (NSTEMI) dengan nilai signifikansi p sebesar 0,000 dalam rentang signifikan $95 \%$ ( $p$ $<0,05)$ dan nilai korelasi $r$ sebesar 0,441 . Hal tersebut menunjukkan korelasi antar skor 
Killip dengan LOS searah, memiliki kekuatan sedang, dan signifikan. Korelasi positif (searah) artinya jika semakin tinggi skor Killip maka lama rawat inap semakin memanjang (> 4 hari).

Hal tersebut sesuai dengan hasil penelitian yang dilakukan di 64 rumah sakit 6 negara timur tengah (Bahrain, Kuwait, Qatar, Oman, United Arab Emirates, dan Yaman), didapatkan jumlah pasien yang tergolong dalam kelas Killip 1, 2, 3, dan 4 berjumlah 6689 pasien bahwa pasien dengan kelas Killip yang tinggi di rumah sakit memiliki pengaruh terhadap lama perawatan secara signifikan pada pasien SKA NSTEMI dan STEMI. Kondisi pasien dengan kelas Killip 1 (78\%) memiliki perbedaan jika dibandingkan dengan kelas Killip 2,3, dan 4 yaitu pada kelas Killip tinggi yang terdiri dari kelas Killip 2 (13\%), kelas Killip 3 (7\%), kelas killip $4(2 \%)$, cenderung memiliki usia lebih tua dan komorbiditas lebih banyak berupa riwayat penyakit arteri koroner, diabetes, hipertensi, dislipidemia, kerusakan ginjal jika dibandingkan dengan Killip 1 (EI Menyar, et al., 2012).

\section{Analisis Perbedaan Korelasi antara} Skor TIMI, GRACE, Killip dan Prognosis Length of Stay (LOS) pada Pasien Sindrom Koroner Akut dengan Non ST Elevation Myocard Infarction (NSTEMI) di RSUD dr. Iskak Tulungagung

Berdasarkan hasil analisis statistik di atas dapat diketahui bahwa terdapat perbedaan korelasi secara signifikan antara TIMI, GRACE, dan Killip sebagai prediktor prognosis (LOS) pada pasien Sindrom Koroner Akut Non ST Elevation Miocard Infarction (SKA NSTEMI) dengan nilai signifikansi berturut-turut adalah skor TIMI $(0,000)$, skor GRACE $(0,000)$, dan skor Killip $(0,000)$ sehingga korelasi signifikan pada rentang $95 \%(p<0,05)$ dengan besar koefisien korelasi TIMI $(r)=$ 0.466, skor GRACE $(r)=0.598$, Killip $(r)=$ 0.441 . Penelitian yang dilakukan oleh Filipiak, et al. (2010) yang membandingkan skor risiko TIMI, GRACE, SIMPLE, BANACH, dan ZWOLLE pada pasien SKA didapatkan hasil bahwa skor GRACE paling baik dalam melihat prognosis pasien dalam jangka panjang dan sudah dikenal oleh tenaga kesehatan.

Panduan dari European Society of Cardiology Clinical Practice Guidelines merekomendasikan skor risiko untuk diagnostik pada pasien SKA NSTEMI dengan menggunakan GRACE (ESC, 2011). Beberapa komponen yang dapat dianalisa dari skor GRACE yang mewakili skor risiko TIMI dan skor Killip, antara lain adanya penilaian usia pasien, deviasi segmen ST pada EKG, kardiak biomarker, kelas Killip, dan terdapat komponen hemodinamik dan disfungsi renal yang hanya terdapat dalam skor risiko GRACE, sedangkan TIMI memiliki kemudahan dalam penggunaan karena terdiri dari dua pilihan dalam pengisian (dikotom), (Khalil, et al., 2009). Berdasarkan hasil penelitian yang dilakukan pada pasien di dengan jenis kelamin perempuan pada usia rata-rata 69,7 tahun sebanyak 869 pasien dengan SKA NSTEMI didapatkan hasil skor GRACE memiliki akurasi yang lebih baik jika dibandingkan dengan skor TIMI (Zhu, et al., 2014). Skor risiko kelas Killip terdiri dari klasifikasi risiko berdasarkan indikator klinis gagal jantung komplikasi dari infark miokard akut, kurang memperhatikan faktor lain di 
luar gagal jantung, biasa dipakai dalam kegiatan sehari-hari, mudah, dan sudah dikenal (PERKI, 2015, Nunez, et al., 2010).

Tabel 4. Parameter yang diukur dari skor Killip, TIMI dan GRACE dalam pemeriksaan pasien dengan SKA NSTEMI

\begin{tabular}{|c|c|c|c|c|}
\hline No & Variabel & Killip & TIMI & GRACE \\
\hline & Parameter & & & \\
\hline & Klinis & & & \\
\hline 1. & Usia & + & + & + \\
\hline 2. & Tekanan darah & + & + & + \\
\hline 3. & $\begin{array}{l}\text { Frekuensi } \\
\text { denyut nadi }\end{array}$ & + & + & + \\
\hline 4. & Ronkhi & + & + & + \\
\hline 5. & Suara murmur & + & + & + \\
\hline 6. & $\begin{array}{l}\text { Saturasi } \\
\text { oksigen }\end{array}$ & + & + & + \\
\hline 7. & $\begin{array}{l}\text { Edem } \\
\text { ekstremitas }\end{array}$ & + & + & + \\
\hline 8. & Temperatur & - & + & + \\
\hline
\end{tabular}

\section{Parameter}

Laboratorium

1. Troponin

2. Kreatinin

3. Gula darah sewaktu

4. HBA1C

5. CKMB

6. Darah lengkap (Hb, leukosit, trombosit )

7. Analisa Gas Darah

8. BUN

9. Albumin

10. SGOT/PT

11. PT/APTT

12. Kultur sputum

13. Kultur darah

14. Elektrolit

15. Tes sputum BTA

\begin{tabular}{|c|c|c|c|c|}
\hline & Parameter & & & \\
\hline & Foto & & & \\
\hline 1. & Foto Thoraks & + & + & + \\
\hline \multirow[t]{3}{*}{2.} & Foto CT scan & - & + & + \\
\hline & Pemeriksaan & & & \\
\hline & Jantung & & & \\
\hline 1. & $\begin{array}{l}\text { Elektrokardiog } \\
\text { ram }\end{array}$ & + & + & + \\
\hline 2. & Angiogram & - & + & + \\
\hline \multirow[t]{3}{*}{3.} & Echocardiografi & + & + & + \\
\hline & TOTAL & 19 & 26 & 28 \\
\hline & PEMERIKSAAN & & & \\
\hline
\end{tabular}

Berdasarkan tabel di atas dapat dilihat skor GRACE memiliki pemeriksaan lebih lengkap dibandingkan skor TIMI dan Killip, sehingga memiliki korelasi paling kuat sebagai prediktor prognosis pasien SKA NSTEMI. Hal tersebut sesuai dengan hasil penelitian yang menunjukkan skor GRACE memiliki nilai signifikansi $p=0.000$ dan koefisien korelasi sedang $(r=0.598)$.

\section{SIMPULAN}

Terdapat perbedaan korelasi yang signifikan antara skor TIMI, GRACE, dan Killipsebagaiprediktorprognosis pada pasien Sindrom Koroner AkutdenganNon ST Elevation Myocard Infarction (NSTEMI) di ICCU RSUD Dr. Iskak Tulungagung, dengan skor GRACE memiliki korelasi paling kuat dengan nilai $r=0.598$. 


\section{DAFTAR PUSTAKA}

Antoni ML, Boden H, Delgado V, Boersma E, Fox K, Schalij MJ, Bax JJ. 2012. Relationship between discharge heart rate and mortality in patients after acute myocardial infarction treated with primary percutaneous coronary intervention. Eur Heart J 2012;33:96-102.doi:10.1093/ euroheartjlehr293.Epub 2011 Aug 22.

Backus, BE., Six, AJ., Kelder, JH., Gibler, WB., Moller,FL., Doevendans, PA. 2011. Risk Scores For Patient With Chest Pain: Evaluation In The Emergency Department. Current cardiology reviews, 2011, vol.7, No.1

Ben, S. H., Ouali, S., Hammas, S., Bougmiza, I., Gribaa, R., Ghannem, K., et al. 2011. Correlation of TIMI risk score with angiographic extent and severity of coronary artery disease in non STelevation acute coronary syndromes. Ann Cardiol Angeiol 2011; 60:87-91.

Bueno, H., Avilles, FF. 2012. Use Of Risk Scores In Acute Coronary Syndromes. Heart 2012 98: 162-168.doi:10.1136/ heartjnl-2011-300129

El-Menyar A.,Zubaid, M., AlMahmeed, W., Sulaiman, K., Alnabti, A., Singh, R., Al, SJ. 2012. Killip Classification in Patients With Acute Coronary Syndrome: Insight From a Multicenter Registry. Am J Emerg Med. 2012 Jan;30(1):97-103. doi: 10.1016/ j.ajem.2010.10.011. Epub 2010 Dec 14

European Society of Cardiology Clinical Practice Guidelines. 2011. Acute Coronary Syndromes (ACS) in patients presenting without persistent ST-segment elevation (management of), Eur. Heart J. 32 (2011) 2999-3054.
Fillipiak KJ., Koltowski L, Grabowski M, Karpinski G, Glowzynska R, Huzcek Z, Kochman J, Majstrak F, et al. 2014. Comparison of the seven-year predictive value of sixrisk scores in acute coronary syndrome patients: GRACE, TIMI, SIMPLE, ZWOLLE, and BANACH. KardiolPol.2014; 72(2):155-65, doi:10.5603/KP.a2013.0216. Epub 2013 Aug 30.

Garcia S, Canoniero M, Peter A, de Marchena E, Ferreira A. Correlation of TIMI risk score with angiographic severity and extent coronary artery disease in patient with non ST-elevation acute coronary syndromes. Am J Cardiol 2004; 93: 813-6

Jensen, MT., Kaiser, C., Sandsten, KE., Alber, H., Wanitshcek, M., Jensen, JS., Pedersen, S., Soerensen, R., et al. 2013. Heart rate at discharge and long-term prognosis following percutaneous coronary intervention in stable and acute coronary syndromes-results from the BASKET PROVE trial. Int J Cardiol 2013; 168:3802-6.

Khalil, R.,Han, Lei., Quan, He. 2009. The use of risk scores for stratification of non-ST elevation acute coronary syndrome patients. exp Clin Cardiol 2009; 14(2): e25-e30.

LaMorte, WW. 2016. Advantages and Disadvantages of Cohort Studies. Boston University School of Public Health

Lakhani, MS., Qadir, F., Hanif, B., Farooq, S., Khan, M. Correlation of Thrombolysis in Myocardial Infarction (TIMI) risk score with extent of coronary artery disease in patients with acute coronary syndrome. J Pak Med Assoc 2010;60:197-200 
Lippi G, Sanchis-Gomar F, Cervellin G. 2016. Chest Pain, Dyspnea and Other Symptoms in Patients With Type 1 and 2 Myocardial Infarction. A literature review. Int J Cardiol 2016;215:20-2

Moghadam, MA., Safari, S., Moghadam, HA. 2016. Screening characteristics of TIMI score in predicting Acute Coronary Syndrome outcome; a diagnostic accuracy study. Emergency. 2017; 5 (1): e18

Nunez, G., Garcia-R., Luaces, M., Vivas,D., Agustin J., Ferrer G., Bordes, S., et al. 2010. Mild heart failure is a mortality marker after a non-ST-segment acute myocardial infarction. Elsevier. European Journal of Internal Medicine 21 (2010) 439-443

Nursalam. 2013. Konsep dan Penerapan Metodologi Penelitian Ilmu Keperawatan. Jakarta. Salemba Medika

PERKI. 2015. Pedoman Tatalaksana Sindrom Koroner Akut. Pehimpunan Dokter Spesialis Kardiovaskular Indonesia
Seronde MF, Geha R, Puymirat E, Chaib A, Simon T, Berard L, Drout E, et al. 2014. Discharge heart rate and mortality after acute myocardial infarction. Am J Med 2014;127: 954-62

World Health Organization (WHO). 2011. Global Atlas on Cardiovascular Disease Prevention and Control. Geneva: World Health Organization, 2011

Xu,t., Zhan, Y., Tan, X. 2016. The Relationship Between Heart Rate and Mortality of Patinets with Acute Coronary Syndromes in the Coronary Intervention Era. Medicine.2016 Nov:95(46):e5371. doi:10.1097/MD.0000000005371

Zhu H, Xue H, Wang H, Chen Y, Zhou S, Tian F, Hu S, Wang J, Yang J, Zhang T. 2015. Risk Stratification and Prognostic Value of GRACE and TIMI risk scores for Female Patients with Non ST segment ElevationAcute Coronary Syndrome. Minerva Cardioangiol. 2015 Jun;63(3): 171-8.Epub2014 Dec 11. 